\title{
Increase in Consumer Debt Preceding Crisis Due to Advancement in Technology, Further Evidence Supporting the Idea No Real Estate Bubble Existed Preceding Crisis Presented by Eddison Walters Risk Expectation Theory of the Global Financial Crisis of 2007 and 2008: The Case for Eddison Walters Modern Economic Analysis Theory
}

\author{
Eddison T. Walters ${ }^{1}$ \\ ${ }^{1}$ Walters Global Business Resources LLC, United States \\ Correspondence: Eddison T. Walters, Dr. Eddison T. Walters, Walters Global Business Resources LLC, 170 NE \\ 2nd Street \#4065 Boca Raton, FL 33429, United States.
}

Received: July 7, 2020

doi:10.5539/ibr.v13n9p122
Accepted: August 20, 2020

Online Published: August 21, 2020

URL: https://doi.org/10.5539/ibr.v13n9p122

\begin{abstract}
The researcher called for economic research to consider the potential effect of advancement in technology on analysis of economic data in Eddison Walters Modern Economic Analysis Theory in the future represented a paradigm shift in economic analysis that will significantly reduce the potential for error due to data distortion in the future. The foundation of the world's economy is based on the sharing of information, yet very little attention has been given to the effect of technology advancement in the analysis of data. The researcher of the current study highlighted the critical nature of sharing information to the development of the world's economy in the past, as well as the critical nature of sharing information to the world's economy today. Advancement in technology has drastically improved the sharing of information and has led to the globalized economy. The lack of evidence supporting the widely accepted theory of the Global Financial Crisis of 2007 and 2008 prompted the investigation by the current researcher aimed at gaining insight into economic factors that were responsible for conditions contributing to the Global Financial Crisis of 2007 and 2008. Walters (2018) presented evidence suggesting no financial bubble existed before the Global Financial Crisis of 2007 and 2008. The study resulted in the development of "Eddison Walters Risk Expectation Theory of The Global Financial Crisis of 2007 and 2008". The theory presented an alternative explanation for the financial crisis. The researcher called for additional investigation to gain insight into the nature of the cause of the Global Financial Crisis of 2007 and 2008. Further investigation in Walters (2019) provided evidence supporting the idea, technological advancement led to the rapid growth in home prices before the Global Financial Crisis of 2007 and 2008. The result from the analysis of data in Walters (2019) revealed the following, 0.989 Adjusted R-square, 194.041 Mean Dependent Variable, 5.908 Square Error of Regression, and 488.726 Sum-of-Square Residual, from nonlinear regression analysis. The dependent variable in the study was, "home purchase price" and the independent variable was, "advancement in technology". The current study continued the investigation into factors that were described in the literature which set the conditions leading to the Global Financial Crisis of 2007 and 2008. Gaining insight into the effect of technological advancement on the significant increase in consumer debt prior to the Global Financial Crisis will significantly contribute to the understanding of the economic environment before the Global Financial Crisis of 2007 and 2008. Insight into the effect of advancement in technology on the increase in consumer lending prior to the Global Financial Crisis of 2007 and 2008, will significantly contribute to the understanding of the Global Financial Crisis of 2007 and 2008.
\end{abstract}

Keywords: advancement in technology, consumer debt, Eddison Walters modern economic analysis theory, global financial crisis of 2007 and 2008, Eddison Walters risk expectation theory of the global financial crisis of 2007 and 2008, real estate bubble, wage stagnation

\section{Introduction}

Advancement in technology has led to significant disruption and a globalized economy today. An investigation into the lack of evidence supporting the widely accepted theory on the Global Financial Crisis of 2007 and 2008 
prompted the investigation by the current researcher to gain insight into economic factors blamed for the conditions leading to the financial crisis in 2008. Walters (2018) presented evidence suggesting, no financial bubble existed prior to the Global Financial Crisis of 2007 and 2008, leading to the development of "Eddison Walters Risk Expectation Theory of the Global Financial Crisis of 2007 and 2008" as an alternative explanation for the crisis which called for additional investigation to gain a true understanding of the crisis.

Further investigation in Walters (2019) provided evidence that suggested, technological advancement led to the rapid growth in home prices prior to the Global Financial Crisis of 2007 and 2008. The result from the analysis of data in Walters (2019) revealed the following, 0.989 Adjusted R-square, 194.041 Mean Dependent Variable, 5.908 Square Error of Regression, and 488.726 Sum-of-Square Residual from nonlinear regression analysis with the dependent variable "home purchase price" and independent variable of "advancement in technology".

The current study continued the investigation into factors, which were suggested to have set the conditions for the financial crisis. The significant increase in consumer lending prior to the financial crisis is one such factor. Gaining insight into the effect of technological advancement on the significant increase in consumer lending prior to the Global Financial Crisis of 2007 and 2008 will significantly contribute to the understanding of the financial crisis. Insight into the effect of technological advancement on the increase in consumer lending prior to the financial crisis will make a significant contribution to the body of knowledge.

\section{Background of Study}

Several questions were raised as a result of the analysis of economic data prior to the Global Financial Crisis of 2007 and 2008 in recent studies that called into question much of current research in the body of literature on the Global Financial Crisis. Overwhelming evidence suggesting, the failure of considering the effect of technological advancement was an error resulting in significant distortion of analysis of data that was collected prior to the financial crisis. As a result of the error, the conclusion of the existence of a real estate bubble prior to the Global Financial Crisis of 2007 and 2008 was a false conclusion. "Eddison Walters Modern Economic Analysis Theory" is a new theory proposed in Walters (2020) to address the error leading to distortion from the analysis of data due to the lack of consideration of the impact of technological advancement on economic data. Eddison Walters Modern Economic Analysis Theory called for the consideration of the effect of technological advancement on economic data analysis to avoid error leading to distortion of data in future economic research. The current research presented additional evidence supporting the development of Eddison Walters Modern Economic Analysis Theory.

\section{Statement of the Problem}

The rapid adaptation of technology in the real estate industry and the mortgage industry in a very short period prior to the Global Financial Crisis of 2007 and 2008 resulted in the rapid increase in home purchase prices in the United States. The lack of consideration of the significant effect of advancement in technology on data prior to the crisis was a significant error by researchers, resulting in a distortion of analysis data. The distortion from the analysis of data led researchers to falsely conclude the existence of a real estate bubble prior to the financial crisis. Eddison Walters Modern Economic Analysis Theory was developed to address errors, which could result in data distortion by the exclusion of such factors in economic research.

\section{Purpose of the Study}

The current study provided additional evidence supporting the development of Eddison Walters Modern Economic Analysis Theory, by considering the effect of advancement in technology on the significant increase in consumer debt prior to the Global Financial Crisis of 2007 and 2008. The knowledge gained from the current research will significantly contribute to the body of literature.

\section{Research Question}

Does the evidence suggest, analysis of consumer debt data preceding the Global Financial Crisis of 2007 and 2008 resulted in error from data distortion, due to the failure to consider the effect of advancement in technology on the data?

\section{Hypothesis}

Ho: The evidence suggested, analysis of consumer debt data preceding the Global Financial Crisis of 2007 and 2008 did not result in error from data distortion, due to the failure to consider the effect of advancement in technology on the data.

Ha: The evidence suggested, analysis of consumer debt data preceding the Global Financial Crisis of 2007 and 2008 resulted in error from data distortion, due to the failure to consider the effect of advancement in 
technology on the data.

\section{Nature of Study and Scope}

The current research was a quantitative investigation using secondary data from the World Bank Database and the United States Federal Reserve Database. The focus of the research was to gain insight into the need to address the issue of error in the economic data analysis, resulting from the lack of consideration of the effect of advancement in technology on data that was analyzed prior to the Global Financial Crisis of 2007 and 2008.

\section{Limitations}

The current study addressed the consideration of factors impacting data, which must be considered by researchers to prevent error in the economic data analysis, which resulted from the lack of consideration of the effect of technology advancement on economic data prior to the Global Financial Crisis of 2007 and 2008.

\section{Literature Review}

Evidence presented in the literature suggested, significant errors from the analysis of data resulted in data distortion, which led to widespread false conclusions regarding the cause of the Global Financial Crisis of 2007 and 2008. Data analysis in Walters (2018) led the researcher to conclude, there was no evidence supporting the idea, foreign capital flowing into developed countries created an abundance of capital that created a financial bubble, causing rapid growth in lending in the United States prior to the Global Financial Crisis of 2007 and 2008. Significant concerns were raised regarding the accuracy of the cause of the financial crisis, which was widely accepted in the body of literature, as a result of the research conducted in Walters (2018), which called for additional investigation.

The alternative theory for the financial crisis, Eddison Walters Risk Expectation Theory of the Global Financial Crisis of 2007 and 2008, was presented by the researcher in Walters (2018). Based on a search of the literature by the researcher in Walters (2018) the lack of evidence supporting the idea of the existence of a real estate bubble emerged as an issue of focus for investigation by the current researcher. The theory presented the idea, false conclusion of a real estate bubble resulting from false information disseminated in the media in the United States, led to the financial crisis in 2007 and 2008.

Both Walters and Djokic (2019) and Walters (2019) furthered developed the Eddison Walters Risk Expectation Theory of the Global Financial Crisis of 2007 and 2008. The researcher analyzed data and concluded, the existence of a real estate bubble prior to the financial crisis was a false conclusion in Walters and Djokic (2019). Subprime mortgage lending and low-interest rates for too long were both ruled out as factors that contributed to the Global Financial Crisis of 2007 and 2008 (Walters and Djokic, 2019; Walters, 2019).

Walters (2019) presented evidence concluding technological advancement was responsible for the rapid growth of home prices prior to the Global Financial Crisis of 2007 and 2008. Straka (2000) was cited in by the study, which chronicled the transformation of the mortgage industry in the United States between 1995 and 2000. As a result of the integration of technological advancement much more efficiency and accessibility to mortgage lending was created (Walters, 2019). Efficiency and accessibility of real estate listings were also significantly improved by the transition from print listings to online listings as presented in Muhanna (2000) (Walters, 2019). The researcher presented evidence from correlation analysis that resulted in, 0.989 Adjusted R-square, 194.041 Mean Dependent Variable, 5.908 Square Error of Regression, and 488.726 Sum-of- Square Residual for the independent variable of "advancement in technology", and the dependent variable of "home purchase price" in Walters (2019).

Walters (2020A) expanded Eddison Walters Risk Expectation Theory of The Global Financial Crisis of 2007 and 2008, with the development of Eddison Walters Modern Economic Analysis Theory. The new theory called for the consideration of the effect of advancement in technology on economic data in all economic analyses to reduce the likelihood of data distortion, leading to false conclusions in economic research, such as the false conclusion of a real estate bubble prior to the financial crisis.

The researcher painted a complete picture of the errors and events leading to the false conclusion of a real estate bubble, along with the media misinformation which caused the Global Financial Crisis of 2007 and 2008, resulting in the collapse of the United States economy and a worldwide economic downturn, which were responsible caused the Great Recession in Walters (2020B). Further analysis of data highlighting key factors helped solidify the idea presented by Eddison Walters Risk Expectation Theory of the Global Financial Crisis of 2007 and 2008. The need to address the issue of the effect of technological advancement in economic data analysis, by Eddison Walters Modern Economic Analysis Theory was confirmed. Key factors contributing to the Global Financial Crisis were highlighted in Walters (2020B). The factors highlighted in the study included 
constant sensationalized claims by economists in the media of a real estate bubble and predictions of a coming real estate collapse, without presenting any evidence supporting the claims (Walters, 2020B). Another critical factor that significantly contributed to the financial crisis highlighted in Walters (2020B) was the ease at which the media ran with the theory of the real estate bubble and predictions of a real estate crash prior to the financial crisis, without demanding evidence in support of the claims. Data analysis presenting record low mortgage delinquencies ninety days past due in danger of being foreclosed at the same time the media predicted doom and gloom in the United States housing market, was also highlighted in Walters (2020B).

The idea, wage stagnation in the United States led consumers to replace the lack of income growth with consumer debt that drove public consumption prior to the Global Financial Crisis of 2007 and 2008 was presents throughout the literature (Guttmann \& Plihon, 2010; Main \& Sufi, 2018; Wisman, 2013). The literature failed to adequately make the case, presenting very little evidence supporting the theory. Widespread claims in the literature pointed to significantly increased consumer debt which was a substitution for the lack of wage growth, as a significant factor contributing to the financial crisis (Guttmann \& Plihon, 2010; Main \& Sufi, 2018; Wisman, 2013).

The entire foundation of the world's economy is based on sharing of information. Kahai, Sara and Kahai (2011) discussed the development of the theory of the firm. The literature cited Porter (1990) that noted, the key source of a firm's competitive advantage, was the value chain of the firm. The value chain is the series of processes that add value to input into the firm, that produces a product for the customer of the firm (Kahai et. Al, 2011). The firm was developed to reduce the significant cost involved with sharing information between large numbers of people in the different processes that comprise the value chain (Kahai et. Al, 2011). A significant challenge for organizations in the past was the capability to share information in a timely manner that allowed information to remain relevant and useful. The ability to share information across an organization departments with a significant number of individuals is referred to, as information reach, and information richness is the ability to disseminate information across the organization in a timely manner, that allowed the information to remain relevant and useful (Kahai et. Al, 2011). Advancement in technology provided firms with the capability to share unlimited information instantly, leading to the deconstruction of the firm's value chain.

The value chain of a firm today is no longer a key source of the firm's competitive advantage, making advancement in technology an even more critical factor in the economy. As a result of technological advancement, today the value chain of the firm has been deconstructed and is no longer critical to competitive advantage, therefore the different processes no longer must locate close to each other (Kahai et. Al, 2011). Processes once a critical part of the value chain of a firm can be conducted anywhere around the world as a result of technological advancement. The main underpinning of economic activity and the primary reason for the development of the theory of the firm was to share information. Advancement in technology has made unlimited information available instantly, therefore the effect of technological advancement must be considered in all analyses of economic data.

Eddison Walters Modern Economic Analysis Theory represents a paradigm shift in the approach to economic data analysis which is long overdue. An approach to economic analysis that does not consider the effect of technological advancement on economic data, in an economic environment where technology is rapidly changing will continue to result in the unreliable analysis of economic data. Advancement in technology has drastically improved the sharing of information on which the entire theory of the firm was developed. The theory of the firm is the foundation of the entire world's economy; therefore, it is critical to consider the effect of technological advancement when analyzing economic data. The ideas presented by Eddison Walters Modern Economic Analysis Theory is long overdue and critical to reliable economic analysis in the future.

\section{Methodology}

The researcher discussed the methodology used in the current study. The researcher identified the population and sample for the research. Sampling procedures, data analysis plans, threats to validity, and ethical procedures were also included in the methodology section. The researcher concluded with a summary.

\section{Research Question}

Does the evidence suggest, analysis of consumer debt data preceding the Global Financial Crisis of 2007 and 2008 resulted in error from data distortion, due to the failure to consider the effect of advancement in technology on the data?

\section{Hypothesis}

Ho: The evidence suggested, analysis of consumer debt data preceding the Global Financial Crisis of 2007 and 2008 did not result in error from data distortion, due to the failure to consider the effect of advancement in technology on the data. 
Ha: The evidence suggested, analysis of consumer debt data preceding the Global Financial Crisis of 2007 and 2008 resulted in error from data distortion, due to the failure to consider the effect of advancement in technology on the data.

\section{Population}

Cellular phone subscription per 100 in the United States was collected from the World Bank database. Consume debt data were collected from the United States Federal Reserve on all consumer debt.

\section{Sampling and Sampling Procedures}

Several variables were analyzed in the study. Cellular phone subscription data per one hundred in the United States collected from the World Bank Database for the period from 1990 to 2006 was analyzed in the study. Consume debt data were collected from the United States Federal Reserve Database on all consumer debt over the same period was analyzed.

\section{Threats to Validity}

The validity of the data for the study was established in the literature. The World Bank Database was established as a reliable source for collecting secondary data in the literature. United States Federal Reserve Database was established as a reliable source for secondary data in the literature. Data analyzed in the study was collected preceded the 2007 crisis to avoid the data being significantly skewed from government intervention policies and the turmoil in the financial market, because the focus was on the impact of technology on the data prior to the Global Financial Crisis of 2007 and 2008.

\section{Ethical Procedures}

Secondary data was collected from the United States Federal Reserve Database and the World Bank Database, which are existing databases. There were no human subjects involved in the research.

\section{Results and Discussion}

Table 1. Total Consumer Credit Owed and Securitized Outstanding, Billions of Dollars, Seasonally Adjusted



\section{Data Analysis Results}

The results of nonlinear correlation analysis in Table 1 showed, 0.996 Adjusted R-square, 1512.683 Mean Dependent Variable, 36.399 Square Error of Regression, and 18548.89 Sum-of-Square Residual, 0.000000 F-Statistic. The results of regression analysis in Table 1 showed a significant correlation between the growth in the independent variable of "mobile cellular subscriptions (per 100 people)" data, and the growth pattern of the dependent variable of "consumer debt" data preceding the Global Financial Crisis of 2007 and 2008.

\section{Hypothesis Testing}

Ho: The evidence suggested, analysis of consumer debt data preceding the Global Financial Crisis of 2007 and 2008 did not result in error from data distortion, due to the failure to consider the effect of advancement in technology on the data. The researcher rejected Ho. 
Ha: The evidence suggested, analysis of consumer debt data preceding the Global Financial Crisis of 2007 and 2008 resulted in error from data distortion, due to the failure to consider the effect of advancement in technology on the data. The researcher failed to reject Ha.

\section{Research Question Result}

The researcher found the evidence support the idea; analysis of consumer debt data preceding the Global Financial Crisis of 2007 and 2008 resulted in error from data distortion due to the failure to consider the effect of advancement in technology on the data.

\section{Discussion}

The researcher concluded, the evidence from the analysis data demonstrated 0.996 Adjusted R-square, which is a near-perfect correlation between advancement in technology and the growth in consumer debt in the United States Prior to the Global Financial crisis of 2007 and 2008. A far more likely explanation for the significant increase in consumer debt prior to the Global Financial Crisis of 2007 and 2008, was the adaptation of technology by lending institutions that made the access to lending easier and widely accessible to the consumer. The evidence suggested a significant increase in consumer debt was simply as a result of convenience. Other attempts to explain the significant increase in consumer debt prior to the Global Financial Crisis and factors contributing to the crisis is completely discredited by the overwhelming evidence presented the literature and the results of the analysis of data in the current study.

The sharing of information has been the pillar of the economy for hundreds of years. As technology advancement continue to evolve, the approach to the analysis of economic data must consider the effect of technological advancement. Eddison Walters Modern Economic Analysis Theory represents a paradigm shift in economic analysis that will significantly reduce the potential for error due to data distortion in the future. The results of nonlinear correlation analysis in Table 1 that showed, 0.996 Adjusted R-square, 1512.683 Mean Dependent Variable, 36.399 Square Error of Regression, and 18548.89 Sum-of-Square Residual, 0.000000 F-Statistic, is further evidence that underscores the need for adapting Eddison Walters Modern Economic Analysis Theory as part of standard practice when analyzing economic data over an extended period of time.

Eddison Walters Modern Economic Analysis Theory underscores the importance of the consideration of technological advancement when analyzing economic data, representing a paradigm shift in the analysis of economic data that will significantly increase the reliability of economic research moving forward. The new theory has potential that can be a key element in avoiding data distortion in economic data analysis in the future. The theory calls for researchers to take steps to consider the effect of technological advancement in economic data analysis moving forward. Researchers can avoid potential data distortion, resulting in significant errors in economic analysis, by addressing the issue of the potential effect of advancement in technology on data. The researcher calls for all economic research to consider adding the potential effect of technological advancement, in the analysis of all economic data in the future. By taking steps to address the issues of potential bias from advancement in technology on economic data, the potential for error in economic analysis will be significantly be reduced in the future.

\section{Conclusion}

Advancement in technology is the most critical element of the economy today. Economic research can no longer only focus on backward-looking historical economic data when conducting economic analysis but must also consider the effect of technological advancement on the evolution of sharing information. The lack of consideration of the effect of technological advancement on economic data can lead to significant distortions from the analysis data. The fact, the entire economy around the world is based on sharing information makes analyzing economic data without consideration of the effect of technology advancement a critical error in economic analysis. The effect of technological advancement on the consumer lending industry, the mortgage industry, and the real estate industry in recent studies, have demonstrated the drastic economic effect of technological advancement on the economy. The comparison of data from two different periods before and after the industries had undergone a significant transformation from advancement in technology, resulted in the comparison of industries that were completely altered. Therefore, researchers were not comparing the same data. Researchers completely disregarded the economic principle behind the Latin phrase "ceteris paribus", meaning all other things being equal, which has been established as a critical principle for conducting reliable data analysis for hundreds of years.

The researcher of the current study concluded, the existence of widespread inaccuracies throughout the entire body of literature on the entire account of the Global Financial Crisis of 2007 and 2008. The researcher calls for the entire body of literature on the Global Financial Crisis to be reconsidered to accurately reflect the true nature of the 
financial crisis. It is critical for researchers to consider the effect of advancement in technology in economic data analysis moving forward, especially in an era of rapid changes in technological advancement, to avoid data distortion resulting in significant errors in economic analysis. The researcher call for all economic research to consider the potential effect of technological advancement on analysis of all economic data in Eddison Walters Modern Economic Analysis Theory in the future, represents a paradigm shift in economic analysis that will significantly reduce the potential for error due to data distortion in the future. By taking steps to address the issues of potential bias from advancement in technology on economic data, the potential for error in economic analysis will be significantly be reduced in the future.

\section{References}

FederalReserve.gov (2020). Federal Reserve. Retrieved from https://www.federalreserve.gov

Guttmann, R., \& Plihon, D. (2010). Consumer debt and financial fragility. International Review of Applied Economics, 24(3), 269-283. https://doi.org/10.1080/02692171003701420

Kahai, S. K., Sara, T. S., \& Kahai, P. S. (2011). Off-Shoring and outsourcing. Journal of Applied Business Research (JABR), 27(1). https://doi.org/10.19030/jabr.v27i1.915

Mian, A., \& Sufi, A. (2018). Finance and business cycles: The credit-driven household demand channel. Working Paper 24322. Cambridge, Mass.: National Bureau of Economic Research. https://doi.org/10.3386/w24322.

Walters, E., \& Djokic, B. (2019). No real estate bubble preceding global financial crisis: Eddison Walters risk expectation theory of the global financial crisis of 2007 and 2008. Journal of International Business and Economics, 7(2), 1-11. Published by American Research Institute for Policy Development. https://doi.org/10.15640/jibe.v7n2a1

Walters, E. T. (2018). Changes in FDI inflows and economic growth and the effect on exports: The aftermath of the global financial crisis of 2007 and 2008 (Order No.10976977). Available from ProQuestOneAcademic. (2135243535). Retrieved from https://search.proquest.com/docview/2135243535?accountd=35796

Walters, E. T. (2019). Growth in home purchase price preceding crisis explained by technology advancement: Eddison Walters risk expectation theory of the global financial crisis of 2007 and 2008 confirmed. Journal of International Business and Economics, 7(2), 140-153. Published by American Research Institute for Policy Development. https://doi.org/10.15640/jibe.v7n2a15

Walters, E. T. (2020). Eddison Walters Modern Economic Analysis Theory: Building on the Eddison Walters Risk Expectation Theory of The Global Financial Crisis of 2007 and 2008. Archives of Business Research, 8(6), 118-126. https://doi.org/10.14738/abr.86.8399

Walters, E. T. (2020B). Impact of advancement in technology, false conclusion of real estate bubble, record low mortgage delinquency irresponsible media, U.S. economic policy disaster: Evidence supporting Eddison Walters risk expectation theory of the global financial crisis of 2007 and 2008. Journal of International Business and Economics, 8. Published by American Research Institute for Policy Development. URL: https://doi.org/

Wisman, J. D. (2013). Wage stagnation, rising inequality and the financial crisis of 2008. Cambridge Journal of Economics, 37, 921-945. https://doi.org/10.1093/cje/bes085

World Bank.org, (2020). World Bank Database. Retrieved from https://data.worldbank.org

\section{Copyrights}

Copyright for this article is retained by the author(s), with first publication rights granted to the journal.

This is an open-access article distributed under the terms and conditions of the Creative Commons Attribution license (http://creativecommons.org/licenses/by/4.0/). 